\title{
Futurising science education: students' experiences from a course on futures thinking and quantum computing
}

\author{
Tapio Rasa ${ }^{1}$ (D) Elina Palmgren ${ }^{2} \cdot$ Antti Laherto $^{1}$ (D)
}

Received: 4 May 2021 / Accepted: 29 November 2021 / Published online: 2 February 2022

(c) The Author(s) 2022, corrected publication 2022

\begin{abstract}
To promote students' value-based agency, responsible science and sustainability, science education must address how students think about their personal and collective futures. However, research has shown that young people find it difficult to fully relate to the future and its possibilities, and few studies have focused on the potential of science education to foster futures thinking and agency. We report on a project that further explored this potential by developing future-oriented science courses drawing on the field of futures studies. Phenomenographic analysis was used on interview data to see what changes upper-secondary school students saw in their futures perceptions and agentic orientations after attending a course which adapted futures thinking skills in the context of quantum computing and technological approaches to global problems. The results show students perceiving the future and technological development as more positive but also more unpredictable, seeing their possibilities for agency as clearer and more promising (especially by identifying with their peers or aspired career paths), and feeling a deeper connection to the otherwise vague idea of futures. Students also felt they had learned to question deterministic thinking and to think more creatively about their own lives as well as technological and non-technological solutions to global problems. Both quantum physics and futures thinking opened new perspectives on uncertainty and probabilistic thinking. Our results provide further validation for a future-oriented approach to science education, and highlight essential synergies between futures thinking skills, agency, and authentic socio-scientific issues in developing science education for the current age.
\end{abstract}

Keywords Futures thinking $\cdot$ Agency $\cdot$ Socioscientific issues $\cdot$ Science teaching $\cdot$ Technology

Tapio Rasa

tapio.rasa@helsinki.fi

1 Department of Education, Faculty of Educational Sciences, University of Helsinki, Siltavuorenpenger 5 A, 00014 Helsinki, Finland

2 Department of Physics, Faculty of Science, University of Helsinki, Helsinki, Finland 


\section{Introduction}

'Everything goes faster and faster' is a pervasive claim and widely shared feeling. In his book 'Social acceleration: A new theory of modernity,' German sociologist Rosa (2013) differentiates and discusses the connections between three mutually reinforcing dimensions of social acceleration: technical acceleration, acceleration of social change, and acceleration of the pace of life. This trend of acceleration, together with emerging global sustainability crises, may explain recent empirical findings on young people's relationship with the future: lack of stable future horizons can lead to hopelessness, directionless actions and inabilities to project oneself into the future (Cook, 2016; Cuzzocrea \& Mandich, 2016; Rubin, 2013).

Such findings are alarming because the same issues that problematise young people's perception of the future-accelerating sociotechnical change and global sustainability crises - also necessitate the ability to keep one's eyes on the horizon while acting in the present. The United Nations' Agenda 2030 programme calls for societal transformations that cannot be achieved without transgenerational thinking, responsibility and transformative agency of the young. Therefore, Education for Sustainable Development (ESD) has been positioned as a key instrument to achieve the sustainable development goals (Unesco, 2017), requiring fundamental rethinking of values, aims and pedagogies of all education (Lotz-Sisitka et al., 2015). This development has contributed to the evolvement of research and practice on science and technology education: taking responsible action and contributing to change have been taken up as important aims of school science (European Commission, 2015; Hodson, 2003; OECD, 2018). Science education should prepare students not only to understand the role of science and informed decision-making in society but also to question societal choices on the basis of ethical consideration and to take action to bring about desirable change (Bencze et al., 2012; Hodson, 2011; Sjöström et al., 2017). In other words, emphasis is given to (transformative) agency, i.e. the capacity for intentional (transformative) action (Emirbayer \& Mische, 1998).

To increase such societal relevance of science education, socio-scientific issues (SSI; Zeidler, 2014) have gained ground in science curricula worldwide. SSIs have proven successful in critically addressing the complex connections between science, technology, society and environment (STSE). Yet, typical forms of SSI and STSE teaching have been criticised as being superficial and thus ineffective in supporting the transformations needed both on the individual and societal level due to global sustainability issues (Hodson, 2011).

Our approach for addressing these concerns in science education is to draw on the concepts and methods of the field of futures studies (e.g. Ahvenharju et al., 2018; Lombardo, 2016; Rubin, 2013). This interdisciplinary field investigates trends, patterns and causes of change and stability in order to develop foresight and create future scenarios. From this field we borrow the notions of 'futures thinking' and 'perception of the future' (see Levrini et al., 2021). These notions typically refer to abilities of disengaging from deterministic future views, understanding the plurality of futures and identifying and questioning assumptions to develop alternative scenarios (see e.g. Bishop et al., 2007; Börjeson et al., 2006; Voros, 2003). In this paper we argue that different types of perceptions of the future and ways of futures thinking deeply influence one's agency.

As promoting sustainability by fostering transformative agency is considered a central objective of science education, and science and technology are typical ingredients in young people's dystopian views (Carter \& Smith, 2003) as well as hopes of sustainable futures (Cook, 2016; Lloyd \& Wallace, 2004), there are great demands and opportunities to 
elaborate futures thinking specifically in science classrooms. However, pedagogies inspired by futures studies have not been adapted in science education until a few initiatives in the recent years (Branchetti et al., 2018; Jones et al., 2012; Levrini et al., 2019, 2021; Lloyd \& Wallace, 2004; Paige \& Lloyd, 2016; Tasquier et al., 2019). The present study originates from one of them: the EU-funded project I SEE. This article especially complements the conceptualisations of Levrini et al. (2021): while based on similar starting points in both context and theoretical foundations, our specific focus is relating futures thinking (and by extension, 'future-scaffolding skills' as formulated by Levrini et al.) to perceptions of technology and agency. In addition, we have aimed to illustrate how future-oriented ways of teaching science apply to topics outside the immediately relevant case of environmental sustainability issues.

To be precise, the aim of the present study was to further explore the potential of science education to foster students' futures thinking and agency by investigating how students experienced a novel course combining the basics of quantum computing and futures thinking; particularly its influence on their futures perception and agentic orientations. The study examined the following research questions:

After participating in a course adapting ways of thinking from futures studies in the context of quantum computing, what kind of changes did the students see in their:

(1) Perception of the future and agency in general?

(2) Perception of the future and agency in relation to science and technology?

Before reporting on the course and the explorative research carried out, we lay the theoretical background by discussing literature on young people's futures thinking and its connections to their agency. We then discuss these issues within the context of science and technology.

\section{Background}

\section{Futures thinking and agency}

Concerns about the difficulties modern-day people have in imagining the future are not new. Already in the 1990s literature showed alarming signs of disintegration of identities due to individuals' changing relationships with time (Sennett, 1998). More recently, Eurobarometer surveys (e.g. Eurobarometer, 2015) have shown shortages in young people's imagination and abilities to project themselves into the future. These worries have been addressed in the fields of futures studies and youth studies, where a number of publications have investigated in depth how young people perceive their own future and the future in general.

Several studies analysing young people's writings on the future (e.g. Angheloiu et al., 2020; Cuzzocrea \& Mandich, 2016) have shown both pessimistic and optimistic views. A common finding has been a duality in futures thinking of the young: personal futures may be seen as positive and in one's own hands, but national and especially global futures as gloomy and out of one's influence (Cook, 2016; Rubin, 2013). This resembles the 'two-track thinking' (Threadgold, 2012) observed in the context of the climate crisis, in which personal futures are conceived unconnected from global long-term futures. Such tendency has been understood as a psychological coping strategy against the fears 
and anxiety associated with the long-term future, and especially global ecological crises (Ojala, 2012). Such hopelessness could be manifestly consequential: in fact, it has been argued that sustainability crises can be attributed to 'a lack of imagination, rather than awareness' (Angheloiu et al., 2020, p. 1).

Perceptions of the future, brought out by the above-mentioned studies, not only manifest an individual's relationship with the future but also guide and motivate choices and actions in the present (Ahvenharju et al., 2018; Lombardo, 2016; Lyon \& Carabelli, 2016; Rubin, 2013). Research has shown how positive images of the future and a perspective of hope strongly connect to seeing new possibilities (Lombardo, 2016; Ojala, 2012). Focusing on threats and negative images of the future, by contrast, narrows down thinking and restricts the number of possibilities perceived. This may lead to 'colonization of the future' (Masini, 1993, p. 8), i.e. the unquestioned future narratives are confirmed as 'reality' (Facer, 2012; Hutchinson, 1996). Empowering students thus relates to making schools 'places of learning to reimagine the world instead of reinforcing it asit-is', where students are equipped to 'face inevitable future uncertainty' (Tomin, 2020, pp. 2-3).

Indeed, scholars in futures studies stress that communities and individuals can cultivate their futures thinking, and several methods for that have been developed (Bishop et al., 2007; Börjeson et al., 2006). Furthermore, a growing body of theoretical literature is bridging such methods or related concepts into education (e.g. Häggström \& Schmidt, 2021). By practising the building of alternative scenarios one can develop future consciousness (Ahvenharju et al., 2018; Lombardo, 2016) and one's preparedness for various futures. Understanding the plurality of futures enables seeing alternatives and opportunities to influence the future (Lloyd \& Wallace, 2004; Lyon \& Carabelli, 2016), as does disengaging from individual-centric thinking (Angheloiu et al., 2020). In "Context and method", we will describe how these methods were adapted in the teaching-learning module which is the context of the present study.

Such opportunities to develop futures thinking appear immediately relevant in regard to agency, which has been promoted as an educational objective, both generally (OECD, 2018; Unesco, 2017) and specifically in science education (European Commission, 2015; Hodson, 2003), in order to enhance active and responsible participation in a complex and uncertain world. Agency connects strongly to futures thinking since agency involves the idea of projection and implies anticipation' (Cuzzocrea \& Mandich, 2016, p. 553); our dreams, hopes and thoughts about the future have an impact on how we act in the present (Lombardo, 2016; Lyon \& Carabelli, 2016; Ojala, 2012).

The concept of agency has various interpretations, but it is common in social science to define it as the capacity for autonomous social action during which people intentionally transform their social and material worlds (e.g. Biesta \& Tedder, 2007; Emirbayer \& Mische, 1998). The present study provides a temporal perspective on this: how do the young perceive the interplay between their agency and surrounding structures of the future?

In their seminal work, Emirbayer and Mische (1998) depicted agency as consisting of three dimensions: iterational, practical-evaluative and projective. The projective dimension of agency acts as a link between futures thinking and transformative agency, as it denotes the ability to imagine alternatives by distancing oneself or breaking free from constraining schemas, habits and traditions (which govern the iterational dimension of agency) (Emirbayer \& Mische, 1998). These can be mapped onto the futures thinking terminology of probable, possible and preferable futures (e.g. Börjeson et al., 2006): similarly to preferable futures, the projective dimension of agency is based on actors' goals, hopes, fears and aspirations. This is the basis of the futures thinking skills of visioning the future and the 
backcasting method (Bishop et al., 2007; Robinson, 1990), widely used in futures studies and applied in the project reported here.

This connection of futures thinking to the temporal dimensions of agency, recently also studied in the context of teacher education (Varpanen et al., 2021), motivates the research approach employed here. Furthermore, agency is often considered not only an individual's but also a community's capacity (e.g. Hoffmann \& Rainio, 2007). In the approach of the project reported here, we focused on the development of students' individual takes on futures and agency, but also investigated the social aspects related to agency and its relationship with surrounding structures.

\section{Role of science and technology in futures}

Conceptions of the future can hardly be discussed without addressing the role of technology in shaping our world. Accordingly, in futures studies technology has long been considered a central cause of systemic change, and conversely future expectations and perceptions of risk have been recognised as factors that steer technological change, knowledge production and educational goals (Borup et al., 2006).

The association of technology and future is certainly not unique to academia: according to a 2016 Finnish Youth Barometer (Myllyniemi, 2017), the claim 'Technology will have a stronger role in our lives a decade from now', is strongly or quite strongly agreed on by $88 \%$ of Finnish 15 to 29 -year-olds, making it the most agreed-upon future claim in the study. Given the current sustainability crises, and the prevalence of both dystopian and utopian future narratives popularised by science fiction or envisioned by expert futurists, it is not surprising that research has shown that the majority of students' fears and deterministic, utopian and dystopian future views are connected to science and technology (Carter $\&$ Smith, 2003). Science and technology also relate in a variety of ways to young people's hopes and dreams about sustainable futures (Cook, 2016; Lloyd \& Wallace, 2004). In Cook's (2016, p. 517) words, 'for young adults technological development can represent a refuge of faith and hope for the future'. Future-oriented science education could, therefore, help support students' evaluations of both promises and perils of science and technology in regard to environment and society. In addition, the formation of new technologies provides a context for discussing authentic science (Kapon et al., 2018) with open questions and possibilities for creativity as well as 'ownership' of emerging technology (Facer, 2012).

Generally speaking, perceptions of technology and the processes that give rise to it differ in the extent to which they permit human influence. In other words, just as views of the future, views of technology may be more or less deterministic. Discourses of technological determinism, which have been subjected to much criticism after the 1960s, are centred around the belief that technology develops along certain 'steps' which are predetermined by possibility rather than directed according to social and human interests (Bauchspies et al., 2006).

A number of conceptualisations of nondeterministic approaches to understanding technology have been proposed, one of which is Bijker's (2001) constructivist view. Bijker's model of 'social construction of technology' (SCOT) counterpoints the deterministic perspective with more nuanced and complex interactions between society and technology, attempting to contextualise technological discourses as constructivist and democratic (see also Hodson, 2003).

Agency is thus inherently present in the SCOT perspective: technology may take a multitude of paths because development, adoption and social shaping of technology happen 
in a technical, cultural and political interaction. Contrasting with strictly techno-dystopian and techno-utopian future horizons, nondeterministic views of technology imply the existence of multiple possible futures and the necessity of identifying preferable futures and acting accordingly, promoting reflective practice.

Thus, in future-oriented education such nondeterministic perspectives are desirable: they could link school science to the possibility of influencing the world in a value-based way rather than merely contributing to a preset trajectory of technological development. Optimally, mirroring the new aims of science education (see "Introduction"), technology could transform from a 'refuge of hope' to a platform of projective agency.

Finally we note that, following the line of reasoning of Hodson (2011) among others, a strict differentiation of technology and science can be problematic. This is especially clear in the case of future-oriented education, where, e.g., envisioned technologies may imply great advances in scientific knowledge. In contrast to the related convention of talking about 'science fiction' rather than 'technology fiction', we have opted to emphasise technology.

\section{Context and method}

\section{Context of the study}

To test an educational approach to fostering students' capacities to imagine the future and to take an active role in it in the context of a contemporary science topic, we developed an experimental teaching-learning module called 'Quantum computers and the future of ICT' (Palmgren et al., 2019). This module was designed and implemented under the European Erasmus + project 'I SEE' (2016-2019) that examined ways of bridging futures studies to science education and implementing future-oriented activities in science classes (Branchetti et al., 2018; Levrini et al., 2021; Tasquier et al., 2018).

The I SEE project was formed by a strategic partnership among eight partners from four European countries (Italy, Finland, Iceland, and the United Kingdom), and its main goal was to address the issues in science education posed by global unsustainability, the uncertainty of the future, and sociotechnical acceleration (Rosa, 2013). To this end, four teaching-learning modules were developed, in which future-oriented thinking was connected to current socio-scientific issues. The module discussed in the present article was developed by us, the Finnish partners, and implemented twice in Finland and once in Italy. The topics of the other three modules were artificial intelligence, carbon sequestration, and climate change. Further information on the project and all module materials are available at https:// iseeproject.eu. A study focusing on the development of future-scaffolding skills during the climate change module has been previously published (Levrini et al., 2021).

Each module developed in the project had different emphases and methods for practising futures thinking. Specific to the module analysed in this article was the emphasis on exercises on systems thinking and scenario building techniques as described in the following. Moreover, the central scientific topic of each module provided some unique opportunities in terms of conceptual and procedural science knowledge. Thus, another aspect specific to the quantum computing module - which is the context of the present study-was emphasis given to the concepts of spin and quantum superposition, with time allotted to learning the meaning of the concepts and making some basic calculations. The topic of quantum computing provided logical continuity from purely scientific knowledge accessible at the 
upper-secondary level to emerging technologies and to future possibilities of these technologies. The scientific topic of the module also tapped into a fruitful synergy in lines of reasoning between quantum physics and futures thinking: both domains require and open up new perspectives on uncertainty and probabilistic thinking.

The data for the present study come from the first module implementation in 2018 in Helsinki, Finland. The module was implemented as an extra-curricular course and it consisted of two subsequent weekends and one evening session. Altogether the length of the course was ca. $20 \mathrm{~h}$. Participants of the course were sought through upper-secondary schools with a STEM specialisation located in the Helsinki region. Based on enrolment order, 22 participants (10 females and 12 males) with ages between 16 and 19 were selected. The course was free of charge for the participants and they were able to include it in their upper-secondary diploma as an optional physics course, assuming their school approved the course. The same students were allowed to participate in the 2019 implementation of the artificial intelligence module, but they were not required to do so.

Before the course started, students wrote a short essay describing what they imagine life is like in 2035. These essays were later revised as a homework exercise. The first course weekend started with an overview lecture introducing the evolution of ICT (information and communication technology) and computing power throughout history, speculating on their possible future development, and guiding students to contemplate the role of technology in changing the society and working life. One aim of this discussion was to help students to identify their current conceptions on the relationship between technology and society. Another aim was to lead students to realise how the then-current technology has shaped the way classical computers use two states (bits) to express information. This technological discussion aimed to bridge the past and present, and lead students' thinking towards possible technological futures. The knowledge of the binary way to represent information was then expanded to simple logic operations and more complicated algorithms.

The historical perspective was utilised also in another activity in which, using old documentaries and movie clips, it was demonstrated how rapid the technological development of the last few decades has been and that these changes have had wide effects on the whole of society. The intention was to encourage students to consider the implications of technological developments for their futures.

A common thread of the course was provided by the projects students worked on in small groups starting from the first day of the course. This activity was spread out throughout the whole module, so that students could put their newly acquired knowledge and skills into practice right away. At first, they were asked to choose a personally relevant and interesting socio-scientific problem to be solved. The teachers of the course formed the small groups based on the problems students had chosen. The groups were encouraged to choose a topic that could in some way involve quantum computing and/or ICT. Yet, through discussion it was immediately noted that any complex issue in modern societies involves a technological element, and students did not have to choose a problem that is primarily technological.

As the first weekend progressed, students studied their chosen problems as part of a complex system, involving multiple different dimensions, such as social, ethical, scientific, environmental and professional. The students were also introduced to some basic ideas of futures studies and creative thinking. Different ways to think about futures were discussed and some historical predictions for technological futures were reviewed. In these activities, it was shown how even experts struggle in predicting the future, why rigid and formal ways of thinking often lead to bad predictions, and that when predicting the future, we 
need to use our imagination and question our assumptions. In order to facilitate more openminded futures thinking and showcase opportunities for action, students familiarised themselves with the idea of the plurality of futures. To illustrate the point, the 'Futures Cone' (Voros, 2003) was introduced. By continuously coming back to the group project, the module attempted to lead students to realise their own potential in taking action to change the future, thus developing ownership of their own future.

During the second course weekend, students were introduced to the central concepts of quantum mechanics, such as spin, superposition and entanglement. Stepping into the quantum realm, they were encouraged to abandon the classical way of thinking and move from causal logic to making probabilistic predictions. After the introduction of the basic concepts, they were guided to make a shift also in computing paradigms and replace bits with qubits (i.e. quantum bits) in expressing information.

The introduction to quantum computing was followed by learning quantum logic gates and simple quantum algorithms. These lessons demonstrated the limits of classical computers in simulating complex systems and showcased new possibilities offered by quantum computers. The explanation of their superior computing power and ability to run complex simulations was linked to the quantum properties previously introduced. Quantum computers were discussed as a new, emerging technology, the possibilities of which are not yet fully realised or even known. This offered an opportunity for students to examine authentic future technology and be in the forefront of learning about it. In order to make quantum computers more tangible, students were guided to use a real quantum processor by IBM that is publicly available over the internet.

Continuing the group work, students were introduced to practical tools for mapping problems and thinking about systems. The broader aim of the activity was to offer students new means of thinking about futures in a changing and complex world, and to support their feeling of agency in their lives. To find more creative ways of thinking about futures, students practised scenario development techniques and imagined several different trajectories of how their chosen problem might evolve with the surrounding society. Students were guided to employ, by turns, three fundamentally different types of thinking methods commonly used in futures studies: probable, possible and preferable futures (Börjeson et al., 2006). During all these methods, the groups were asked to consider the whole system they had built around their chosen problem using systems thinking. When generating probable futures, students extrapolated the current trends in order to anticipate how the future is likely to be if the present-day assumptions remain. Possible futures (what could be) were created by questioning those assumptions and by searching for alternatives and opportunities for influence using "what if" - thinking. In the last scenario building exercise, students imagined preferable futures (what should be) by visioning, starting off from their own values, hopes and dreams. They leaped into a future where their problem has been solved, imagined themselves in that future and contemplated what else has changed in the system.

In the final exercise of the course, the students created a route to the future where their problem has been solved. This exercise employed the backcasting technique (see e.g. Bishop et al., 2007; Robinson, 1990), i.e. going step-by-step backwards from the preferable future to the present, pinning down what phases and obstacles were encountered along the way and how they were overcome. In this process, students were asked to imagine themselves as active participants in the changes through which the desirable future was reached. The aim of this activity was to support students' imagination and empower them to take an active role in influencing their personal as well as global futures.

During the final 'evening session' of the course, groups presented their solutions to the chosen socio-scientific problems and the roles of different stakeholders, including the 
students themselves, in making these changes happen. The presentations, all 'success stories' told in past tense, dealt with the colonisation of Mars, genetic engineering, sustainable energy, recycling, cyber security, and the pensions crisis. All the topics dealt in part with ICT based solutions and many groups included applications of quantum computing in their narratives. After the presentations, the student groups received feedback from the teachers and the topics were discussed together before closing the course.

A more detailed description of the module and all the teaching materials are provided in Palmgren et al. (2019).

\section{Data collection and analysis}

To investigate students' perceptions on their futures thinking and its development during the course, we carried out individual, semi-structured, in-depth interviews approximately a week after the end of the course. Due to the explorative nature of the study, the interview questions were designed to make students consider the course and express their perceptions from a variety of viewpoints. The first part of the interview reviewed the course as a whole, while the second part focused on futures thinking. In this part, the students were also asked about the essay they had first written before the course and later revised as homework. Some final questions addressed students' willingness to pursue STEM careers and what they thought about the role of quantum computers in the future. (For more details, see the interview protocol in Appendix 1.) Students were also asked to solve a conceptual quantum physics problem - this confirmed that all students achieved sufficient knowledge of quantum concepts considering the short duration of the course.

All 22 students were interviewed individually and the interviews were audio-recorded. However, one interview was omitted from analysis due to being incomplete. All other data were transcribed with student names replaced with pseudonyms for the analysis phase. All these students (or with underage students, also their guardian) gave a written consent to participate.

To focus on students' own sense-making of changes they themselves perceived in their thinking, we employed phenomenographic analysis (Marton, 1981) on the interview transcripts. Following Marton's conceptualisation, phenomenography is explicitly about how something is experienced rather than what it is, thus mirroring our second-order research focus (i.e. students' perceptions of changes in their thinking).

We began our analysis by finding passages that could be interpreted as self-reported changes in students' perceptions over the course. Typically these were passages that explicitly referred to, or answers to questions that referred to changes of thinking, but e.g. references to course materials were also considered. To illustrate this process, we present two brief passages that we will return to later. Note in the first passage how Henry does not explicitly state that his thinking has changed, but it is implied by recapitulating ideas from the course. Meanwhile, the passage from Ellen directly addresses a change in one's thinking ('taught', 'develop').

Interviewer: What tools or skills or concepts related to futures thinking, if any, did you learn over the course?

Henry: [...] Well, I can remember really well that image with one present and many futures and then there's the plausible and preferable. And especially the whole idea of there actually being an infinite number of futures.

Ellen: Scenario thinking [...] was kind of the same as when we looked at the [quantum logic] gates, you had to be open to even the really illogical options. So, they both kind of taught, helped develop a kind of creative thinking. 
The database formed this way was scrutinised by two researchers, with irrelevant passages omitted. We then began coding these passages with broad descriptive phrases. After completing this phase, passages were discussed to find stable patterns to form more specific coding. These patterns, such as the plurality of futures and creative thinking (see the two examples above) were then turned into analysable themes, with all three authors negotiating to create a codebook that was used to check each passage against coding criteria. The formation of the themes was guided by the research questions and the above-referred literature on young people's perceptions of futures and agency in general, and perceptions regarding science and technology in particular. Thereby, the process formed a combination of inductive and deductive approaches, typical for qualitative content analysis (Braun \& Clarke, 2006). While coding the passages, the themes and their descriptions were iteratively elaborated in close interaction between the three authors. This process resulted in our final 16 themes (see Table 1), after we opted to omit themes occurring in less than five interviews.

To structure the presentation of the 16 themes in our "Results" section, the themes were grouped into categories. Six such categories were formed, corresponding to different aspects of our research questions, with four and two categories linking to the first and second research question respectively.

As this process also identified redundancies and ill-defined themes, the three researchers negotiated the interpretations until a shared understanding was reached regarding both the themes emerging from the data in general and the coding of each individual passage. Passages rich in nuance could be attributed to multiple themes. The resulting themes and categories still share overlapping qualities, which we will point out explicitly or by interpreting one quotation under multiple themes. Similarly, we have attempted to provide rationale for the formation of some themes by discussing illustrative quotations in closer detail. Finally, pseudonyms and exemplary quotes were translated into English.

\section{Results}

An overview of the results of our analysis is shown in Table 1. The table presents all 16 themes identified in the content analysis. Each theme has been given a descriptive name, grouped into categories of 2-3 themes under both research questions, and the prevalence of the theme (i.e. in what percentage of the 21 interviews the theme was identified) is shown.

\section{General perception of the future}

This category consists of three themes related to self-reported changes in students' conceptions about the future on a broad level: seeing the future as more positive, unpredictable or meaningful. A frequently identified theme is 1A More optimistic or hopeful outlook on the future (52\%), in which students compare their pre-course and current views and find either a generally more optimistic outlook or mitigation of their previous fears and worries. An example comes from Samuel:

There were so many people, like smart and nice people, so I thought that since they have all these good ideas and if they really put them into practice, maybe the world could become a better place. So, it gave me like a positive feeling. 


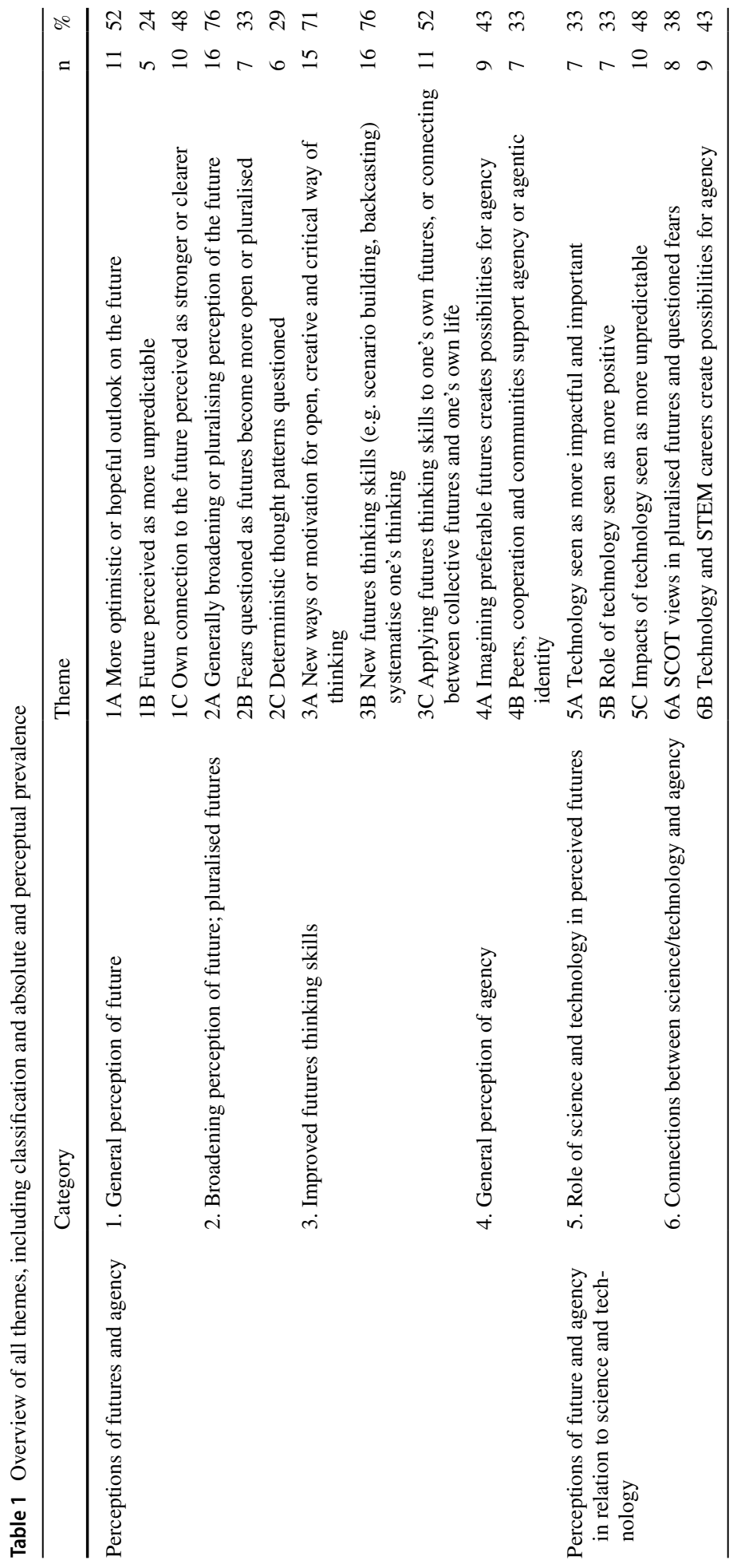


Characteristically for this theme, we note that a change in one's general feeling may come through an experiential process. For Samuel, it seems to be the experience of working together with other students and imagining positive outcomes that has given him more hope. This connection of hope, agency and peers is further explored through theme 4B. Another connected theme is $2 \mathrm{~B}$ : for some students, positivity emerged in the construction of alternative scenarios, and reasoning that one's worries would be shared by others. As one student said about his fears for the future, 'if things start changing in some direction, then probably people start to notice'.

Some students reported changes in their thinking regarding the unpredictability of the future. Indeed, thinking about pluralistic futures (see category 2) is inherently linked to thinking about uncertainty. This theme, IB Future perceived as more unpredictable (24\%), is captured in this quotation from Nora:

It's like I feel that I know even less, I mean in a good way, not like I felt before like I really know, but now I'm even more like, anything can happen.

The feeling that 'anything can happen' repeats in the data, which might be attributed to the course encouraging students to consider multiple possible scenarios and drawing attention to the accelerating pace of social and technological change. In fact, some students commented that they used to think the world would not radically change anymore, but that past decades show that especially sociotechnical changes are fast and hard to predict.

While some students found an open-ended future distressing, some expressed surprise at feeling at peace with unpredictability, perhaps even finding it liberating or relieving (see also theme 2B). For example, Ellen outlines a change in her 'general readiness' to cope with uncertainty. She herself describes this as a qualitative, outside-the-box change in her thinking:

If I thought about the future or tried to predict it, it was like hit-or-miss, but now it feels much more certain [...] like it doesn't matter if what I predicted is what actually happens, just the fact that I have thought about it helps me prepare for whatever it is that comes. So I feel I kind of learned a new way of thinking, like a different process.

Relatedly, the theme $1 C$ Own connection to the future perceived as stronger or clearer (48\%) contains various kinds of expressions related to perceptions of the proximity, relevance or 'realness' of futures:

[...] of course I think about the future occasionally, but I don't know if I automatically think of, like you know a sort of creative future? Maybe my thinking is more slave-like in a way, I think about things from the future perspective but not necessarily about what really happens in the future. (Henry)

Maybe I now think more about what I really want, how I want my life to be and how I could get there, and it's no longer so foggy and absurd to think about the whole thing. That there will be a day I'll actually be 35 or 36 [...] it feels weird. (Vivian)

In our view, such excerpts relate to one's relationship with thinking about futures. One's future can be seen in a 'slave-like' manner, where it is always afar in the distance, relaying demands for the present. Seeing the future as a more fully-formed world that one will come to exist in, not only a symbol of responsibility for one's actions in the present, is what we might call 'inhabiting' the future. Vivian, in her quotation, 'inhabits' her future in a very explicit way, projecting herself into it. Similarly to Vivian, other students expressed newfound motivation about futures thinking, usually finding meaning in this activity through dreams and aspirations. 


\section{Broadened perception of the future; pluralised futures}

The second category consists of three themes connected to taking steps from a onedimensional, uncomplicated futures view towards a broader, pluralised perspective. While related to perceptions of unpredictability, this category focuses on questioning one's assumptions about futures. The theme $2 A$ Generally broadening or pluralising perception of the future (76\%) contains unspecific notions to this end, such as 'it's not just two or three alternatives that can happen'. Many students called back to how the plurality of futures was discussed during the course (the 'Futures Cone' visualisationsee Voros, 2003):

Well, I can remember really well that image with one present and many futures and then there's the plausible and preferable. And especially the whole idea of there actually being an infinite number of futures. (Henry)

Other students made similar comments regarding the 'number' of futures and the limitations of black-and-white thinking.

We also identified two more specific themes related to the pluralisation of futures. One of these is $2 B$ Fears questioned as futures become more open or pluralised (33\%). This sense of relief that may come from stepping out of inflexible narratives is summarised by the following excerpt:

I think the most important lesson was that it's worthwhile to think about different alternatives and sort of widen your perspective and not just think about that worstcase scenario that's on the news [...] but also think really wild thoughts about what could happen. (Aaron)

Here, Aaron is contrasting a wider perspective with what he sees as a more limited narrative offered to him by the surrounding culture. Relatedly, many students addressed the apparent paradox that open-endedness appears as a positive rather than distressing factor. Nora, whose notion that 'anything can happen' we quoted earlier, continued with the following remark:

[...] so of course there is uncertainty, there are also maybe more negative possi-

bilities than I used to think, but [...] solutions can be found anywhere too.

We would be curious to know what causes this bias towards optimism when futures are pluralised. In our view, it might be related to the belief that from a wider range of positive and negative possibilities, some positive one is likely to be found and actualised through human planning and action.

Another specific theme related to widened perspectives on the future is $2 C$ Deterministic thought patterns questioned (29\%). Some students reflected on their previously held views that we might classify as deterministic. A clear comparison with plurality is provided by Aaron:

[...] maybe previously I thought that there's no use thinking about the future because it will come eventually and there's nothing you can do about it. But maybe I now think like it might be useful [and] interesting to think about different scenarios.

In addition to questioning the futility of thinking about the future or trying to make a difference, students noted that even the most probable future is not bound to happen. 


\section{Improved futures thinking skills}

In this category, we grouped three closely linked themes focusing on perceived changes in the skills and mindset one employs in navigating the abstract nature of futures thinking. The theme $3 A$ New ways or motivation for open, creative and critical way of thinking $(71 \%)$ is marked by students feeling they have learned or found new inspiration to think more creatively. One student said she wanted to learn how to not 'get stuck with what currently seems possible', while another felt he learned to see interesting possibilities. A third student, Ellen, used an interesting analogy to explain her thinking:

Scenario thinking [...] was kind of the same as when we looked at the [quantum logic] gates, you had to be open to even the really illogical options. So, they both kind of taught, helped develop a kind of creative thinking.

We recognise that certain intellectual courage needed for open-ended thinking is present in various aspects of the module-both in future-oriented and conceptual activities. Ellen found new tools and confidence for abstract thinking by this analogy with quantum computing and by working on tasks that explicitly encouraged openness to possibilities. Other students reflected on the permission to 'break rules', systematically questioning assumptions, or 'finding the middle ground between crazy and not-so-crazy ideas'.

We also identified recurring reflections on the usefulness of thinking tools discussed and workshopped during the course. These excerpts were coded $3 B$ New futures thinking skills (e.g. scenario building, backcasting) systematise one's thinking (76\%), providing a rather straightforward relationship between lesson content and self-reported changes of perception. Based on the data, the method of backcasting (see "Context and method") seems to have left a lasting impression. As we have noted, the 'Futures Cone' was seen as a useful tool in understanding the probabilistic nature of predicting futures. Some students commented that they did not previously have a (structured) way to think about futures, and that the concept of such tools in itself was illuminating:

I have a more concrete idea that there are these tools, even concrete tools for thinking of the future. [...] This perception of futures thinking was completely new to me before this course, so well, it did affect me very much in that sense. (Marcus)

We also identified students reporting changes in the thinking tools they use in relating their personal future to global future trajectories. This theme, $3 C$ Applying futures thinking skills to one's own futures, or connecting between collective futures and one's own life (52\%), is characterised well by Alexander:

[I learned] to keep in mind that, like many different things involve many risks of what can happen, and that it's hard to make any really long-term plans for your own life even. Because something even really unusual might happen.

This quotation was coded under this theme based on the idea that Alexander has come to think of his own life path as similarly open-ended and hard to predict, possibly because the surrounding world influences his own future, or possibly simply by analogy.

Additionally, students reflected that their futures thinking used to be myopically confined to the 'next step' (what to do after graduating), but now they made connections to sociotechnical trends (for an example, see Joel's quotation in theme 5C) or the usefulness of thinking about aspects of the future that are not immediately relevant. These 
students thus addressed the challenge of 'two-track thinking' (see "Futures thinking and agency"), while taking steps towards 'inhabiting the future'.

\section{General perception of agency}

This category deals with perceptions connected to agency, especially one's own (see "Futures thinking and agency"). We identified three themes, each in some way addressing the connection of agentic orientation to futures thinking, collaborative experiences or imagining one's own future.

The theme 4A Imagining preferable futures creates possibilities for agency (43\%) is related to making goal-oriented choices. Essential for this category is students expressing that imagination prompts action or specifically projective agency: values rather than shortterm evaluation inspire one's agency. Some students, like Lydia, exemplify this theme in referring to the method of backcasting:

I'd just always thought that you go with 'small steps' going forward, but if you start from there in the perfect image, it's really good to start from there and like, how you get there.

While the idea of backcasting seemed to be at the forefront of students' recollections of the course, this theme is also present in technological scenarios students discussed during the interviews (see themes $5 \mathrm{~A}-5 \mathrm{~B}$ ) and reflections on the connection between agency and imagination, such as the following quote from Vivian:

[The course] emphasised that we really can influence things and it's worthwhile to think about in advance, about what will happen. But yeah, maybe it has affected my, like given an empowering kind of perspective on it.

Interestingly, students' reflections attribute agency in different ways. While we are here mainly concerned with students' agency (rather than their beliefs on who else has agency), interviewed students also considered the agency of larger communities they are part of. The idea that one has agency through some larger entity is the focus of the theme $4 B$ Peers, cooperation and communities support agency or agentic identity (33\%).

In this theme we see students clearly identifying with value-based, projective agency: 'I got this feeling doing the group project, like our group could really have influence on this.' However, a recurring perspective in students' reflections is that one person is not enough to bring about desired changes. As Ellen said when explaining her data security concerns: 'I could not make all this happen by myself, it would take a lot more people and time'.

Another pattern we recognised is attributing agency to one's own generation as one that will come to facilitate positive changes. For many students, working together on plans to positively influence the world and discussing large-scale issues was a source of hope (see theme 1A):

[We were] a group of young people, trying to solve these problems, so maybe not all of them are so dumb, so [laughs], maybe that [positive] perspective is becoming stronger. (Joanna)

In seeing their generation as more informed and willing to act, students seemed to challenge the dissonance between their values and their perceptions of societal trends: 
A new generation is coming in [...] people of the same age usually have the same opinion about things. So I noticed how good the ideas they had were and how positively they thought about slowing down climate change [...] I think it's really positive compared to like twenty or thirty years ago. (Oscar)

As students phrased this positive sense of 'generational community' as a new addition to their futures views, we get the sense that they have previously felt relatively alone with their hopes and worries. One student even said he used to think there is no point in trying to mitigate environmental harm, but since there are 'like-minded people', he now considers it worthwhile.

\section{Role of science and technology in perceived futures}

This category consists of three themes regarding the extent, desirability and predictability of technological change. An increased emphasis on the importance of technology (or specifically quantum computing) is the focus of the theme 5A Technology seen as more impactful and important (33\%).

For example, when asked about how he sees quantum computing's possible influence, Samuel said it 'basically will revolutionise the world [...] it might improve things or make them worse, you never know'. Some students shared the perception of such an upcoming revolution. For some students, what changed their perspective was considering the last few decades of technological development or the experience of studying up-and-coming technologies and imagining near-term sociotechnical futures.

Considering technology a more important factor in shaping the world urged many students to also consider the pros and cons of emerging technologies. Students mostly saw technology as a neutral or generally positive force, and the theme 5B Role of technology seen as more positive (33\%) occurs often enough to warrant analysis. For Lydia, technology now appeared more positive because she saw its potential to address more diverse and meaningful human needs:

I don't think so negatively of technology, it's like, my thinking is now a lot more positive [...] It's not just 'there will be robots' but you can develop [technology] a lot like in other ways than just robots coming to work in coffee shops, you know.

Students reported seeing technology as a source of solutions (a perspective explicitly addressed in the course structure), or not as threatening as they previously thought. Views where transformative effects of technological change were seen as more moderate than before were reported: a 'robot uprising' and the loss of real human connection were questioned, or it was considered that positive effects could be uncoupled from negative or disruptive ones.

However, just as students' increased and broadened futures thinking ushered in aspects of unpredictability (1B), an analogous theme emerges here: 5C Impacts of technology seen as more unpredictable (33\%). We have already quoted Samuel's thought that (quantum) technology 'might improve things or make them worse, you never know.' For Joel, this perspective was linked to realising his own two-track thinking:

I used to just think [...] I'll get into a university, right, but I haven't thought [...] if in a hundred years computers have developed this much, then what can happen in another one hundred or even twenty years [...] it's an inspiring and frightening thought at the same time. 
Technological change was seen by some students as inherently hard to predict, especially in the case of quantum computing:

Years ago we couldn't really see that computers would ever be used by anyone or for anything, so now I dare not say that quantum computers aren't going to be used for anything [...] We've been wrong here before. (Marcus)

One student noted that only history will tell how great an impact new technologies have, and another student expressed fears about quantum computers breaking encryption and humanity being superseded by artificial intelligence. While optimistic outlooks on technology were linked to opportunities, these pessimistic scenarios were described in somewhat deterministic terms, which brings us to our sixth and final category.

\section{Role of science and technology in agency}

Finally, we present two themes that connect agency to technology and STEM careers. The theme 6A SCOT views in pluralised futures and questioned fears is centered around the idea that humans have influence over technological change. As we have argued (see "Role of science and technology in futures"), SCOT views link strongly to agency. Bringing the idea of groundbreaking research and innovation into the domain of one's imagination, the course had invited students to claim a level of human ownership of technology: technology could be a reaction to the world instead of the world merely reacting to technology. As Sarah noted when asked if the course affected her technological concerns:

Well, all of the project presentations dealt with these issues, and they had like really realistic scenarios about how these things can be improved.

To explain their thinking, or in referring to projects and discussions from the course, students presented visions of artificial intelligences that safely control private data, new approaches to responsible resource use or ocean cleanup, democratic regulation of technology and so on. As Lydia puts it, the course had suggested that humans can and ultimately do steer technology:

[...] we shouldn't be so black-and-white [about technology] [...] basically robots can't start a revolution unless there's a human behind it.

A final theme links technology to students' own transformative agency in a concrete way: $6 B$ Technology and STEM careers create possibilities for agency. While students' preexisting career plans created diverse contexts for changes in their perceptions, we were able to limit our coding to cases where desirable societal or global futures were linked to one's own agency:

I want to study engineering of some kind, and I hope that with this technology stuff I could be able to develop something myself, that helps people and society generally. (Nora)

Outside some ambiguous cases, students expressed technological agency beliefs quite exclusively in career-focused terms: studying persistently and working hard were seen as necessary conditions to having an influence on societal futures. Ellen, for example, could now see herself contributing to development related to her main concern, data privacy: 
[...] I started feeling more confident in my skills. [...] Because during the course I found out that there is still stuff we don't know [...] if I get an education in like math and physics, then I'll be needed. So that kinda calmed me down a bit.

Some students' reflections on agency were not as detailed, referring to hopes of generally 'making the world a better place', or new perspectives to how the scientific and technological worlds operate: emerging fields and the collaborative nature of research and innovation were seen as avenues for utilising one's strengths and following one's dreams.

\section{Discussion}

This study explored an approach aimed at fostering students' futures thinking and agency in science education. We reported students' self-reported changes in their perceptions after participating in an upper secondary school course on futures thinking and quantum computing. Based on our results, the students saw the course have various effects on their perception of futures and agency. Students considered their views of the future more positive and in some cases uncertain, while generally feeling more connected to the idea of futures. Futures were seen in a more pluralised manner, which was connected to questioning fears, determinism and static futures. More creative and structured ways of thinking were reported regarding both personal and global futures. The course was seen as having affected perceptions of agency, especially through imagining futures and relating to communities and peers. In addition, the students reported changes in views of science and technology in relation to the importance, positivity and unpredictability of technological change, nondeterministic technological views, and ways of influencing the world through STEM careers.

A number of differences set the present study apart from earlier research connecting futures thinking to science education (Jones et al., 2012; Levrini et al., 2019, 2021; Lloyd \& Wallace, 2004; Paige \& Lloyd, 2016). Firstly, our study makes the novel contribution of connecting futures thinking skills and perceptions of technology to students' agency. New approaches are also built into the module design: these include a focus on learning to think about probable, possible and preferable futures (Börjeson et al., 2006) as well as operating in the intersection of two seemingly distinct domains: quantum mechanics and futures thinking. Specific to science education, this showed a number of fruitful synergies between these domains: the course was centred on promoting a leap in thinking, escaping simplistic conventions, working with probabilistic processes related to uncertainty, and wondering what lies beyond the limits of current knowledge. Through such connections and considerations, our study further demonstrates the potential of science education as a context for practising futures thinking.

Our analysis also shows patterns similar to many earlier studies. Students found the future coming 'within their reach'-their perceived connection to the future was strengthened. Similar outcomes have been reported in other studies within the I SEE project (Branchetti et al., 2018). Additionally, many of the 'future-scaffolding skills' operationalised by Levrini et al. (2021) can, in fact, be mapped to our inductively formed thematic analysis: for example, somewhat analogously to the phenomenon of the future 'becoming closer', we used the term 'inhabiting' the future when referring to cases where students perceived that they became able to position themselves into their images of the future. This ability is significant, as it may be interpreted as countering the 'colonization of the future' (Masini, 
1993, p. 8). Perhaps relatedly, students reported newfound interest in learning to think more deeply about futures, echoing results by Angheloiu et al. (2020).

Our results partly reflect the course contents, thus providing tentative validation for our practical approach to future-oriented science education. The results also indicate other aspects of students' experiences on the course. Namely, while learning futures thinking skills and approaching a more transformative agentic orientation towards (global) futures are expected results, we recognise perceptions of uncertainty and the significance of communities and peers as themes that were not expected to arise from the data.

The results regarding unpredictability are pedagogically interesting. In our view, they do not necessarily indicate an insurmountable ethical dilemma in future-oriented education (i.e. making students scared and uneasy) as much as they point out a challenge to be addressed by such pedagogies. From this perspective it is very promising to observe students reflecting on their reactions to perceptions of uncertainty (see quotes under themes $1 \mathrm{~B}, 2 \mathrm{~B})$. Indeed, as something of a proof-of-concept observation, 'learning to accept and cope with the uncertainty of the future' is a higher-level learning goal in our vision for future-oriented education. Simply leaving students with the impression that 'anything can happen' is counterproductive; rather, students should reconcile uncertainty with agency and sense of community, promoting the idea that 'solutions can be found anywhere' (see theme 2B). Both generally and sociotechnically, a future that is not set is open to transformative agency and creativity. Interestingly, the role of facing uncertainty is not clearly addressed in the otherwise quite 'comprehensive picture of goals that science education can and should prioritize' formulated by Levrini et al., (2021, p. 305).

Based on our results, we agree with Cook's (2016) claim that hope is a crucial part of young adults' futures perceptions and should be paired with concern and will to act. Additionally, while beyond the scope of our article, there is much to say about the idea that hopelessness related to global crises can be navigated by identifying as the generation that will solve them (cf. Angheloiu et al., 2020). Further research and theoretical work is needed to validate the significance of such generational identity in the formation of an individual's agency. We again emphasise that there seems to be a social component to our course's effect on students' thinking: in addition to learning futures thinking tools and imagining desirable trajectories, working together in the context of the future seems to create hope. Thus discussions of agency should consider not only personal agency, but also shared agency (Hoffmann \& Rainio, 2007).

The approach explored in this study seems to provide useful synergies between futures thinking skills, agency, authentic sociotechnical issues and conceptually challenging science education. Students found creativity and 'rule-breaking' a refreshing addition to learning science - the future-oriented approach represented science as open-ended and imaginative. However, some students explicitly stated that they did not see enough connection between lessons focusing on futures thinking and those on quantum computing. One challenge may be the choice of scientific context, as quantum computing is an abstract and conceptually challenging subject that was not familiar to students before the course. Our aim on the course was to make the topic as practical as possible but as there are not many applications yet, the topic might have been left too abstract to students. Strengthening the connection of the scientific context to the scenario-building exercises should be paid additional attention to in forthcoming future-oriented science education modules, developed e.g. in the currently ongoing FEDORA project (https://fedora-project.eu).

We also must point out that the structure of the course probably nudged students to consider technology a more important but also more positive factor in global futures (see 
themes 5A, 5B). While the course aimed to provide critical takes on sociotechnical changes and naive hopes of 'technological fix', in further development of future-oriented science education these perspectives should be given full attention, through promoting agency and SCOT views. Also, our participants cannot be taken as a representative of their age group, as they were found to be a homogeneous group of students already interested in the course topics.

Our main approach for supporting the trustworthiness of the study is, as typical for qualitative content analyses (Elo et al., 2014), reporting both the context and the process of analysis accurately. The number and profile of the participants of the research are presented, and the possible biases discussed. Conformability and transferability-see the criteria for trustworthiness as presented by Elo et al. (2014) — are supported by describing in detail the process aiming at a shared understanding among the researchers (see section "Data collection and analysis") and by problematising the generalisation of results to wider groups.

Moving forward, we hope to see further maturation of future-oriented science education in research and practice. As this explorative study focused on students' self-reported changes of thinking, further studies with improved empirical validity should be designed (cf. Levrini et al., 2021). A framework intended for that purpose is currently being constructed within the FEDORA project. Research should be carried out with more precise instruments and a more heterogeneous population of students, exploring how pedagogies for futures thinking and agency are best implemented. Theoretically, the connections between science education, future-oriented pedagogies, sustainability education, SSI/STSE and agency should be thoroughly inspected. We hope the present paper provides some necessary groundwork for these advancements and paves the way for the next step needed to render science education transformative: understanding how improved futures thinking turns to action, i.e. moving from mental future orientation to practical future making.

Supplementary Information The online version contains supplementary material available at https://doi. org/10.1007/s11251-021-09572-3.

Acknowledgements We acknowledge Pia Erkko for transcribing and translating the interviews and carrying out a tentative analysis of the data. The upper secondary school course investigated here was developed and implemented by the expert group consisting of Arto Hellas, Johanna Jauhiainen, Timo Kärkkäinen, Tuomas Puranen, Tiina Ranta-aho, Kimmo Tuominen, and the authors of this article. We also thank the colleagues of the I SEE project (iseeproject.eu), coordinated by Olivia Levrini, University of Bologna, for their support in the course development. Finally, our warmest thanks to the upper secondary school students participating in the course. This work was supported by the European Commission Erasmus+ programme under Grant Agreement no. 2016-1-IT02-KA201-024373); and the European Commission Horizon 2020 programme under Grant Agreement no. 872841. The authors declare no potential conflicts of interest.

Funding Open Access funding provided by University of Helsinki including Helsinki University Central Hospital. This work was supported by the European Commission Erasmus + programme under Grant Agreement no. 2016-1-IT02-KA201-024373); and the European Commission Horizon2020 programme under Grant Agreement no. 872841.

Data availability The datasets generated during the current study are available in the Zenodo repository, https://doi.org/10.5281/zenodo.4734160.

\section{Declarations}

Conflict of interest The authors declare that they have no conflict of interest. 
Open Access This article is licensed under a Creative Commons Attribution 4.0 International License, which permits use, sharing, adaptation, distribution and reproduction in any medium or format, as long as you give appropriate credit to the original author(s) and the source, provide a link to the Creative Commons licence, and indicate if changes were made. The images or other third party material in this article are included in the article's Creative Commons licence, unless indicated otherwise in a credit line to the material. If material is not included in the article's Creative Commons licence and your intended use is not permitted by statutory regulation or exceeds the permitted use, you will need to obtain permission directly from the copyright holder. To view a copy of this licence, visit http://creativecommons.org/licenses/by/4.0/.

\section{References}

Ahvenharju, S., Minkkinen, M., \& Lalot, F. (2018). The five dimensions of futures consciousness. Futures, 104, 1-113. https://doi.org/10.1016/j.futures.2018.06.010

Angheloiu, C., Sheldrick, L., \& Tennant, M. (2020). Future tense: Exploring dissonance in young people's images of the future through design futures methods. Futures, 117, 102527. https://doi.org/10.1016/j. futures.2020.102527

Bauchspies, W. K., Croissant, J., \& Restivo, S. (2006). Science, technology and society: A sociological approach. Blackwell.

Bencze, L., Sperling, E., \& Carter, L. (2012). Students' research-informed socio-scientific activism: Re/ visions for a sustainable future. Research in Science Education, 42(1), 129-148. https://doi.org/10. $1007 / \mathrm{s} 11165-011-9260-3$

Biesta, G., \& Tedder, M. (2007). Agency and learning in the lifecourse: Towards an ecological perspective. Studies in the Education of Adults, 39(2), 132-149. https://doi.org/10.1080/02660830.2007.11661545

Bijker, W. E. (2001). Understanding technological culture through a constructivist view of science, technology, and society. In S. H. Cutcliffe \& C. Mitcham (Eds.), Visions of STS: Counterpoints in science, technology and society (pp. 19-34). State University of New York Press.

Bishop, P., Hines, A., \& Collins, T. (2007). The current state of scenario development: An overview of techniques. Foresight, 9(1), 5-25. https://doi.org/10.1108/14636680710727516

Börjeson, L., Höjer, M., Dreborg, K., Ekvall, T., \& Finnveden, G. (2006). Scenario types and techniques: Towards a user's guide. Futures, 38(7), 723-739. https://doi.org/10.1016/j.futures.2005.12.002

Borup, M., Brown, N., Konrad, K., \& van Lente, H. (2006). The sociology of expectations in science and technology. Technology Analysis \&amp; Strategic Management, 18(3-4), 285-298. https://doi.org/10. 1080/09537320600777002

Branchetti, L., Cutler, M., Laherto, A., Levrini, O., Palmgren, E. K., Tasquier, G., \& Wilson, C. (2018). The I SEE project: An approach to futurize STEM education. Visions for Sustainability, 9, 10-26. https:// doi.org/10.13135/2384-8677/2770

Braun, V., \& Clarke, V. (2006). Using thematic analysis in psychology. Qualitative Research in Psychology, 3(2), 77-101. https://doi.org/10.1191/1478088706qp063oa

Carter, L., \& Smith, C. (2003). Revisioning science education from a science studies and futures perspective. Journal of Futures Studies, 7(4), 45-54.

Cook, J. (2016). Young adults' hopes for the long-term future: From re-enchantment with technology to faith in humanity. Journal of Youth Studies, 19(4), 517-532. https://doi.org/10.1080/13676261.2015. 1083959

Cuzzocrea, V., \& Mandich, G. (2016). Students' narratives of the future: Imagined mobilities as forms of youth agency? Journal of Youth Studies, 19(4), 552-567. https://doi.org/10.1080/13676261.2015. 1098773

Elo, S., Kääriäinen, M., Kanste, O., Pölkki, T., Utriainen, K., \& Kyngäs, H. (2014). Qualitative Content Analysis: A focus on trustworthiness. SAGE Open. https://doi.org/10.1177/2158244014522633

Emirbayer, M., \& Mische, A. (1998). What is agency? American Journal of Sociology, 103(4), 962-1023. https://doi.org/10.1086/231294

Eurobarometer. (2015). Public opinion on future innovations, science and technology (Aggregate report): Eurobarometer qualitative study. http://ec.europa.eu/commfrontoffice/publicopinion/archives/quali/ql_ futureofscience_en.pdf

European Commission. (2015). Science education for responsible citizenship. Report to the European Commission of the expert group on science education. Office of the European Union.

Facer, K. (2012). Taking the 21st century seriously: Young people, education and socio-technical futures. Oxford Review of Education, 38(1), 97-113. https://doi.org/10.1080/03054985.2011.577951 
Häggström, M., \& Schmidt, C. (2021). Futures literacy: To belong, participate and act! An educational perspective. Futures, 132, 102813. https://doi.org/10.1016/j.futures.2021.102813

Hodson, D. (2003). Time for action: Science education for an alternative future. International Journal of Science Education, 25(6), 645-670. https://doi.org/10.1080/09500690305021

Hodson, D. (2011). Looking to the future: Building a curriculum for social activism. Sense Publishers.

Hoffmann, R., \& Rainio, A. P. (2007). "It doesn't matter what part you play, it just matters that you're there". Towards shared agency in narrative play activity in school. In R. Alanen \& S. Pöyhänen (Eds.), Language in action: Vygotsky and Leontievian legacy today (pp. 308-328). Cambridge Scholars Publishing.

Hutchinson, F. (1996). Educating beyond violent futures. Routledge.

Jones, A., Buntting, C., Hipkins, R., McKim, A., Conner, L., \& Saunders, K. (2012). Developing students' futures thinking in science education. Research in Science Education, 42(4), 687-708. https://doi.org/ 10.1007/s11165-011-9214-9

Kapon, S., Laherto, A., \& Levrini, O. (2018). Disciplinary authenticity and personal relevance in school science. Science Education, 102(5), 1077-1106.

Levrini, O., Tasquier, G., Barelli, E., Laherto, A., Palmgren, E., Branchetti, L., \& Wilson, C. (2021). Recognition and operationalization of Future-Scaffolding Skills: Results from an empirical study of a teaching-learning module on climate change and futures thinking. Science Education, 105(2), 281-308.

Levrini, O., Tasquier, G., Branchetti, L., \& Barelli, E. (2019). Developing future-scaffolding skills through science education. International Journal of Science Education, 41(18), 2647-2674. https://doi.org/10. 1080/09500693.2019.1693080

Lloyd, D., \& Wallace, J. (2004). Imaging the future of science education: The case for making futures studies explicit in student learning. Studies in Science Education, 40(1), 139-177. https://doi.org/10.1080/ 03057260408560205

Lombardo, T. (2016). Future consciousness: The path to purposeful evolution: An introduction. World Futures Review, 8(3), 116-140. https://doi.org/10.1177/1946756716673636

Lotz-Sisitka, H., Wals, A. E., Kronlid, D., \& McGarry, D. (2015). Transformative, transgressive social learning: Rethinking higher education pedagogy in times of systemic global dysfunction. Current Opinion in Environmental Sustainability, 16, 73-80. https://doi.org/10.1016/j.cosust.2015.07.018

Lyon, D., \& Carabelli, G. (2016). Researching young people's orientations to the future: The methodological challenges of using arts practice. Qualitative Research, 16(4), 430-445. https://doi.org/10.1177/ 1468794115587393

Marton, F. (1981). Phenomenography: Describing conceptions of the world around us. Instructional Science, 10(2), 177-200. https://doi.org/10.1007/BF00132516

Masini, E. (1993). Why future studies? Grey Seal.

Myllyniemi, S. (2017). Katse tulevaisuudessa: Nuorisobarometri 2016. Grano Oy.

OECD. (2018). The future of education and skills: Education 2030. OECD Education Working Papers.

Ojala, M. (2012). Hope and climate change: The importance of hope for environmental engagement among young people. Environmental Education Research, 18(5), 625-642. https://doi.org/10.1080/13504622. 2011.637157

Paige, K., \& Lloyd, D. (2016). Use of future scenarios as a pedagogical approach for science teacher education. Research in Science Education, 46(2), 263-285. https://doi.org/10.1007/s11165-015-9505-7

Palmgren, E., Laherto, A., Tuominen, K., \& Puranen, T. (2019). Quantum computing and the future of ICT: Teaching-learning module. University of Helsinki/I SEE project. https://iseeproject.eu/wp-content/ uploads/2019/08/O2_ISEE_module_Quantum_computing_and_the_future_of_ICT_EN.pdf

Robinson, J. B. (1990). Futures under glass: A recipe for people who hate to predict. Futures, 22(8), 820842. https://doi.org/10.1016/0016-3287(90)90018-D

Rosa, H. (2013). Social acceleration: A new theory of modernity. Columbia University Press.

Rubin, A. (2013). Hidden, inconsistent, and influential: Images of the future in changing times. Futures, 45, S38-S44. https://doi.org/10.1016/j.futures.2012.11.011

Sennett, R. (1998). The corrosion of character: The personal consequences of work in the new capitalism. Norton.

Sjöström, J., Frerichs, N., Zuin, V., \& Eilks, I. (2017). Use of the concept of Bildung in the international science education literature, its potential, and implications for teaching and learning. Studies in Science Education, 53(2), 165-192. https://doi.org/10.1080/03057267.2017.1384649

Tasquier, G., Branchetti, L., \& Levrini, O. (2019). Frantic standstill and lack of future: How can science education take care of students' distopic perceptions of time? In E. McLoughlin, O. E. Finlayson, S. Erduran, \& P. Childs (Eds.), Bridging research and practice in science education Contributions from science education research (Vol. 6, pp. 205-224). Springer. https://doi.org/10.1007/978-3-030-17219$0 \_13$ 
Tasquier, G., Levrini, O., Laherto, A., Wilson, C., \& Palmgren, E. (2018). The challenge of working with the future within STEM education. In J. Kay \& R. Luckin (Eds.), Rethinking learning in the digital age: Making the learning sciences count, 13th International Conference of the Learning Sciences (ICLS) 2018 (pp. 1441-1442). International Society of the Learning Sciences. https://doi.org/10. $22318 / \operatorname{cscl} 2018.1441$

Threadgold, S. (2012). 'I reckon my life will be easy, but my kids will be buggered': Ambivalence in young people's positive perceptions of individual futures and their visions of environmental collapse. Journal of Youth Studies, 15(1), 17-32. https://doi.org/10.1080/13676261.2011.618490

Tomin, B. (2020). Worlds in the Making: World Building, Hope, and Collaborative Uncertainty. Journal of the American Association for the Advancement of Curriculum Studies (JAAACS), 14(1). https://doi.org/ 10.14288/jaaacs.v14i1.192633

Unesco (2017). Education for Sustainable Development Goals: Learning objectives. Unesco. https://unesd oc.unesco.org/ark:/48223/pf0000247444

Varpanen, J., Laherto, A., Hilppö, J. \& Ukkonen-Mikkola, T. (2021). Teacher agency and futures thinking. Manuscript submitted.

Voros, J. (2003). A generic foresight process framework. Foresight, 5(3), 10-21. https://doi.org/10.1108/ 14636680310698379

Zeidler, D. L. (2014). Socioscientific issues as a curriculum emphasis: Theory, research and practice. In N. G. Lederman \& S. K. Abell (Eds.), Handbook of research on science education (Vol. 2, pp. 697-726). Routledge.

Publisher's Note Springer Nature remains neutral with regard to jurisdictional claims in published maps and institutional affiliations. 